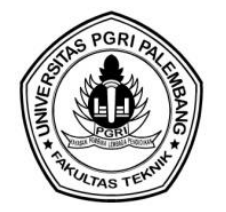

\title{
PENGARUH PENAMBAHAN SERBUK BIJI KARET TERHADAP KUAT GESER TANAH MERAH
}

\author{
Aliyan Saputra Jaya ${ }^{1}$, Amiwarti ${ }^{2}$, Reffanda Kurniawan Rustam ${ }^{3}$ \\ Program Studi Teknik Sipil, Fakultas Teknik Universitas PGRI Palembang \\ "Corresponding Author, Email: amiwartiishak@gmail.com
}

\begin{abstract}
ABSTRAK
Tanah merupakan bagian dari kerak bumi yang tersusun dari mineral dan bahan-bahan organik. Tanah merah daerah Pakjo termasuk ke dalam jenis tanah lempung lunak dengan kuat geser yang rendah. Oleh karena itu tujuan penelitian ini adalah untuk mengetahui seberapa besar kuat geser tanah merah yang terjadi apabila ditambahkan serbuk biji karet ke tanah merah dengan persentase 5\%, 10\%, 15\%, 20\%, $25 \%$. Penelitian dilakukan di laboratorium dengan menggunakan pengujian pemadatan tanah dan pengujian kuat geser (direct shear). Dari hasil pengujian didapat bahwa tanah merah didaerah Pakjo Kota Palembang memiliki nilai kadar air $(\omega)$ sebesar $27,70 \%$, berat jenis tanah $\left(G_{s}\right) \quad 2,67$, batas cair $(L L) \quad 63,35 \%$, batas plastis (PL) 25,13\%, dan indeks plastisitas (IP) 38,22\%. Dan berdasarkan sistem klasifikasi USCS termasuk kedalam klasifikasi tanah lempung $(\mathrm{CH})$, sedangkan berdasarkan sistem klasifikasi AASHTO adalah A-7-6 (clavey soils). Dengan pengujian pemadatan tanah standar (PTS) didapat kadar air optimum $24 \%$ dan berat isi kering optimum 1,634 $\mathrm{gr} / \mathrm{cm}^{3}$. Dari pengujian direct shear disimpulkan bahwa tanah merah dicampur dengan serbuk biji karet sebesar 15\% dapat meningkatkan kuat geser tanah merah dengan kuat geser $(\tau)$ sebesar 65,70 kPa, nilai kohesi (c) 49,00 kPa dan nilai sudut geser dalam ( $\phi$ ) 38,01
\end{abstract}

Kata Kunci: Tanah Merah, Serbuk Biji Karet, Kuat Geser.

\begin{abstract}
Soil is part of the earth's crust which is composed of minerals and organic materials. The red soil of the Pakjo area is a soft clay type with low shear strength. Therefore, the purpose of this study was to determine how much shear strength of red soil that occurs when rubber seed powder is added to red soil with a percentage of $5 \%, 10 \%, 15 \%, 20 \%, 25 \%$. The research was conducted in the laboratory using soil compaction testing and shear strength testing (direct shear). From the test results, it was found that the red soil in the Pakjo area of Palembang City had a water content ( $\omega)$ value of 27.70\%, soil density (Gs) 2.67, liquid limit (LL) 63.35\%, plastic limit (PL) $25,13 \%$, and the plasticity index (IP) $38.22 \%$. And based on the USCS classification system it is classified as clay $(\mathrm{CH})$, while based on the AASHTO classification system is A-7-6 (clavey soils). With the standard soil compaction test (PTS), the optimum moisture content was obtained $24 \%$ and the optimum dry content weight was $1.634 \mathrm{gr} / \mathrm{cm} 3$. From the direct shear test, it was concluded that the red soil mixed with rubber seed powder by $15 \%$ could increase the shear strength of the red soil with the shear strength $(\tau)$ of $65.70 \mathrm{kPa}$, the cohesion value (c) $49.00 \mathrm{kPa}$ and the inner shear angle value $(\phi) 38.01^{\circ}$
\end{abstract}

Keywords: Red Soil, Rubber Seed Powder, Shear Strength

\section{PENDAHULUAN}

Tanah merupakan bagian yang sangat penting sebelum dilakukannya suatu proses pembangunan, karena kerusakan-kerusakan yang terjadi pada bangunan gedung dan jalan seperti terangkat atau turunnya pondasi dan retaknya dinding bangunan, dapat disebabkan oleh tanah yang ada di bawah struktur bangunan sehingga terjadinya suatu pergeseran. Tanah adalah merupakan lapisan paling luar kulit bumi yang biasanya bersifat tak padu 
(unconsolidated), mempunyai tebal mulai dari selaput tipis sampai lebih dari tiga meter yang berbeda dengan bahan di bawahnya, biasanya dalam hal warna, sifat fisik, susunan kimia, mungkin juga proses-proses kimia yang sedang berlangsung, sifat biologi, reaksi dan morfologinya (Darmawijaya, 1990). Tanah merah merupakan tanah podsolik merah kuning, latosols, lateritik, dan mediteran merah kuning. Tanah ini dapat dijumpai pada daerah berombak hingga pegunungan, dan dapat terbentuk dari bahan induk masam hingga basis (Driessen dan Soepraptoharjo dalam Prasetyo, 2009). Di Kota Palembang khususnya daerah Pakjo, salah satu jenis tanah yang cukup banyak yang umum adalah jenis tanah merah yang berupa tanah lempung lunak, yaitu jenis tanah yang mempunyai daya dukung rendah tetapi tinggi kompresibilitas, dimana kandungan mineral lempung dan airnya yang tinggi, tetapi kuat geser tanahnya rendah (Rustam dkk, 2019). Dari penelitian Rustam \& Amiwarti (2017), menyimpulkan bahwa dari pengujian Direct Shear tanah merah di daerah pakjo mendapatkan hasil kohesi $(\mathrm{c}=13,25-16,15 \mathrm{kPa})$, sudut geser dalam $\left(\phi=13,25^{\circ}-16,25^{\circ}\right)$, kuat geser $(\mathrm{t}=15,32-18,25 \mathrm{kPa})$. Dan hasil pengujian Triaxial yaitu kohesi $(\mathrm{c}=16,25-18,15 \mathrm{kPa})$, sudut geser dalam $\left(\phi=13,50^{\circ}-14,75^{\circ}\right)$, kuat geser $(\mathrm{t}$ $=17,68-24,02 \mathrm{kPa}$ ), dimana dari nilai kuat geser tanah merah yang dihasilkan menunjukkan bahwa tanah merah Pakjo termasuk tanah lunak (12,5-25 $\mathrm{kPa})$ dan pada analisa perhitungan penahan tanah, kestabilan lereng, dan daya dukung tanah dibutuhkan parameter seperti sudut geser dalam $(\phi)$, kohesi (c), dan kuat geser $(\tau)$. Dan untuk meningkatkan kuat geser tanahnya perlu ada alternatif penambahan campuran bahan lain, dan salah satunya dalam penelitian ini adalah menggunakan serbuk biji karet dengan penelitian skala laboratorium

Tujuan penelitian ini adalah mengetahui berapa besar pengaruh penambahan serbuk biji karet dengan persentase 5\%, 10\%, 15\%, 20\%, 25\% terhadap kuat geser tanah merah daerah Pakjo Palembang, di mana dengan penambahan campuran serbuk biji karet ke dalam tanah merah diharapkan dapat meningkatkan nilai kuat geser dan daya dukung tanah merah.

Sistem klasifikasi tanah merupakan sistem penggolongan yang sistematis dari jenisjenis tanah yamg mempunyai sifat-sifat yang sama kedalam kelompok dan sub kelompok bedasarkan pemakaiannya. Tujuan dari klasifikasi tanah adalah untuk membedakan jenisjenis tanah dengan cara mengelompokkan tanah sesuai dengan sifat-sifat yang ada, seperti sifat ukuran butiran tanah dan sifat plastisitas tanah. Klasifikasi tanah juga berguna untuk studi yang lebih terpinci mengenai kependapatan tanah tersebut serta kebutuhan akan pengujian untuk menentukan sifat teknik tanah seperti karakteristik pemadatan, kekuatan tanah, berat isi dan sebagainya (Bowles 1989). Sistem klasifikasi tanah ada empat yaitu Brish Standard (BS), American Standar Testing Manual (ASTM), Unifed Soil Classifikasion System (USCS) dan American Association of State Higway and Tranfortation Officials (AASHTO). Dan yang umum digunakan adalah sistem USCS dan AASHTO. Di mana pada sistem klasifikasi tanah AASHTO terbagi kedalam tujuh kelompok tanah, yaitu A-1 sampai A-7, sedangkan pada Sistem Klasifikasi Tanah USCS terbagi ke dalam dua kelompok yaitu tanah berbutir halus (fine grained soil) dan tanah berbutir kasar (coarse grained soil) (Rustam \& Amiwarti, 2017). Purwanto, dkk (2020), dalam penelitiannya melakukan pengujian tanah yang diambil dari daerah Pakjo Way 
Hitam, Palembang Kota, Provinsi Sumatera Selatan, dan hasilnya adalah tanah tersebut tanah lempung lunak, termasuk dalam tanah clay $(\mathrm{CH})$ menurut USCS dan tanah clavey soils (A-7-6) menurut AASHTO. Dan dari hasil pengujian indeks properties, tanah yang lolos saringan No. 200 (82,56\%), kadar air ( $\omega)$ 27,70\%, berat jenis tanah (Gs) 2,67, batas cair (LL) 66,00\%, batas plastis (PL) 25,13\%, indeks plastis (IP) 40,87\%, nilai kadar air optimum (

Menurut Das (2008), kuat geser tanah adalah gaya dengan fungsi menahan tanah agar tidak terjadi keruntuhan, dimana kekuatan geser massa tanah merupakan perlawanan tanah secara internal terhadap keruntuhan atau pergeseran tanah sepanjang bidang geser, dan tanah yang diberi beban akan membuat tegangan geser menahan keruntuhan tanah. Menurut Rustam dkk. (2020), kekuatan geser tanah adalah sifat tanah yang sangat penting dalam mekanika tanah, penggunaan kekuatan geser terutama di dalam permasalahan yang berhubungan dengan: (a) kapasitas daya dukung tanah, pada pondasi dangkal dan pondasi dalam; (b) mobilisasi tekanan tanah lateral, pada tekanan tanah aktif dan tekanan tanah pasif tanah; dan (c) permasalahan kestabilan lereng di daerah galian dan timbunan. Tegangan geser yang mencapai batas maksimal cenderung terjadi keruntuhan dan apabila bidang lereng, maka akan terjadi longsor. Kuat geser dinyatakan dalam rumus: $\mathrm{S}=\mathrm{c}{ }^{+}+$ $\sigma^{\prime} \tan \varphi^{\prime}$. dengan S (Kuat Geser Tanah); U (Tekanan Air Pori); $\sigma$ (Tegangan Total); $\sigma^{\prime}$ (Tegangan Efektip); $\sigma$ " (Sudut Geser Dalam); c' (=Kohesi)

Biji karet merupakan limbah perkebunan yang memiliki bentuk yang seperti lingkaran, di mana terdapat dalam setiap ruang buah pohon karet dengan jumlah setiap bijinya yang berkisar tiga dan enam buah sesuai dengan jumlah ruang. Ukuran biji besar dengan tekstur kulit yang keras, berwarna coklat kehitaman bercak-bercak pola yang khas, dengan sifat dikotilnya merupakan akar tunggang (Lindawati, 2018).

\section{METODE PENELITIAN}

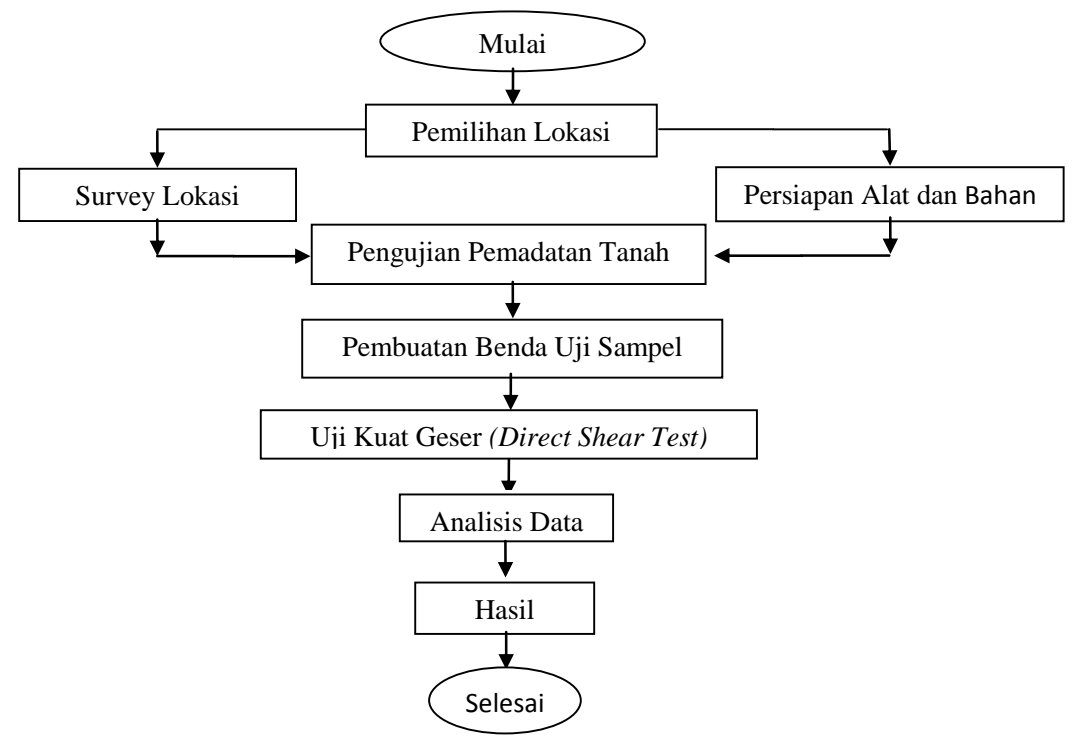

Gambar 1. Diagram Alir Penelitian 
Metode penelitian dijelaskan pada Gambar 1. Pengujian yang dilakukan di laboratorium Mekanika Tanah Universitas Sriwijaya Indralaya ini dilakukan untuk mengidentifikasi dan mengklasifikasikan sifat-sifat sampel tanah yang diambil, dimana pengujian indeks propertis untuk mendapatkan kadar air (water content, $\omega$ ), berat jenis (specific gravity, Gs), batas cair dan batas plastis (Liquid Limit dan Plastic Limit), dan dan indeks plastisitas. Klasifikasi tanah yang digunakan adalah standar USCS dan AASHTO. Setelah sifat fisik tanah merah diketahui, maka dilakukan pengujian kuat geser tanah yaitu dengan pengujian Direct Shear (geser langsung) dengan parameternya adalah $\phi$ (sudut geser dalam) dan c (kohesi) dari tanah.
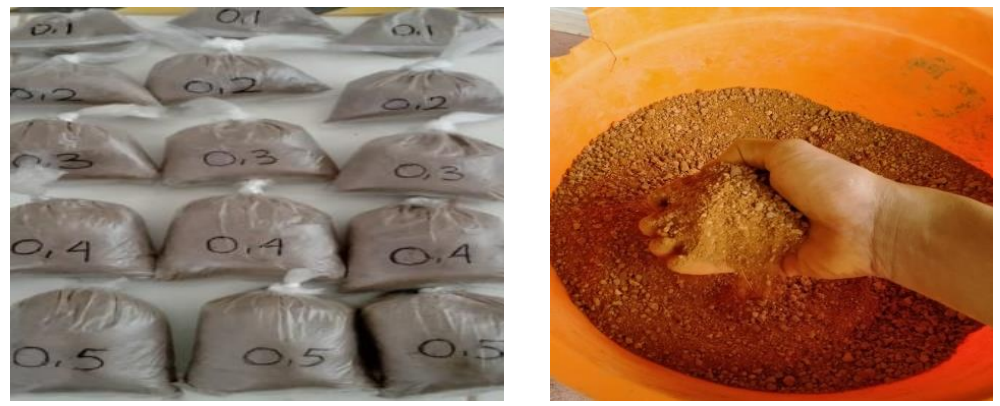

Gambar 2. Sampel Tanah Campuran Serbuk Biji Karet

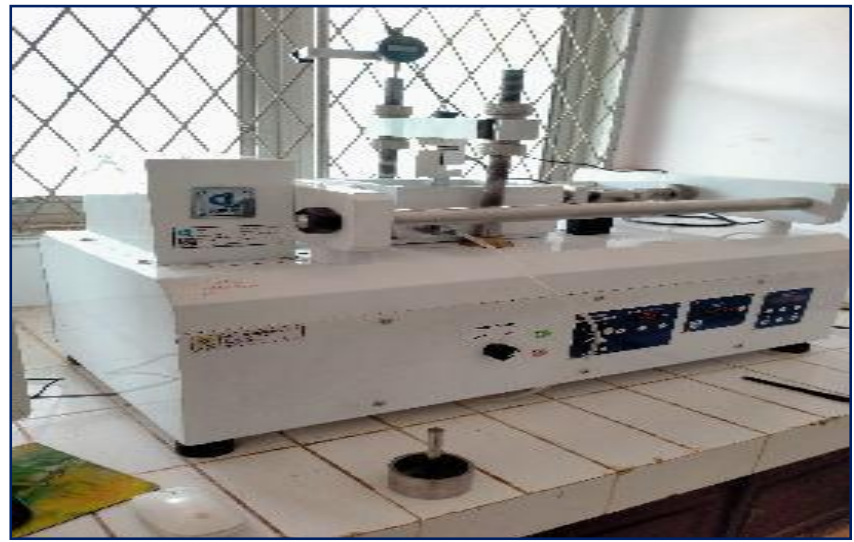

Gambar 3. Alat Digital Direct Shear Test GLDS-02

Masing-masing sampel dibuat dengan penambahan serbuk biji karet sebanyak 5\%, $10 \%, 15 \%, 20 \%$ dan 25\%. Dimana tanah yang telah dikeringkan dan diayak di saringan nomor 4 kemudian dicampur dengan serbuk biji karet (SBK), dengan persentase penambahan campuran ditentukan berdasarkan rumus : $\{\% \mathrm{SB} K=\%$ penambahan $\mathrm{X}$ Ws $\}$. Sehingga banyaknya serbuk biji karet yang digunakan untuk setiap $2 \mathrm{~kg}$ campuran tanah dan SBK, pada kondisi penambahan 5\% diperlukan tanah $1,9 \mathrm{~kg}$ dan SBK 0,1 kg, campuran $10 \%$ tanah 1,8 $\mathrm{kg}$ dan SBK 0,2 kg, campuran $15 \%$ tanah $1,7 \mathrm{~kg}$ dan SBK 0,3 $\mathrm{kg}$, campuran $20 \%$ tanah $1,6 \mathrm{~kg}$ dan SBK 0,4 kg, campuran $25 \%$ tanah $1,5 \mathrm{~kg}$ dan SBK 0,5 kg. Sampel benda uji didapat dengan menggunakan cetakan berdiameter 4", kapasitas $943 \mathrm{~cm}^{3}$. Kemudian sampel dilakukan pengujian dengan diberi beban 2,5 $\mathrm{kg}$, $5 \mathrm{~kg}$ dan $10 \mathrm{~kg}$ 


\section{HASIL DAN PEMBAHASAN}

\section{Hasil Pengujian indeks propertis dan Klasifikasi}

Pengujian untuk penentuan indeks propertis tanah yaitu kadar air tanah $(\omega, \%)$, berat jenis (Gs), analisa butiran, batas cair (LL, \%) dan batas plastis (PL, \%). Juga klasifikasi tanah berdasarkan AASHTO dan USCS. Hasil pengujian indeks propertis dan klasifikasi tanah tergambar pada tabel 1 berikut:

Tabel 1. Indeks propertis dan klasifikasi tanah

\begin{tabular}{|l|l|}
\hline \multicolumn{1}{|c|}{ Pengujian } & \multicolumn{1}{c|}{ Hasil } \\
\hline Kadar Air Asli $(\omega)$ & $27,70 \%$ \\
\hline Berat Jenis Tanah (Gs) & 2,67 \\
\hline Tanah yang Lolos Saringan No.4 & $99,88 \%$ \\
\hline Tanah yang Lolos Saringan No.200 & $82,56 \%$ \\
\hline Batas Cair (LL) & $63,35 \%$ \\
\hline Batas Plastis (PL) & $25,13 \%$ \\
\hline Indeks Plastis (IP) & $38,22 \%$ \\
\hline Klasifikasi Menurut USCS & CH (lempung gemuk) \\
\hline Klasifikasi Menurut AASHTO & A-7-6 (clavey soils) kriteria tanah sangat buruk \\
\hline
\end{tabular}

\section{Hasil Pengujian Pemadatan Tanah Standar.}

Pengujian ini dilakukan untuk mengetahui kadar air optimum dan berat isi kering optimum tanah merah, dimana pada gambar 4 menunjukkan bahwa kadar air optimum

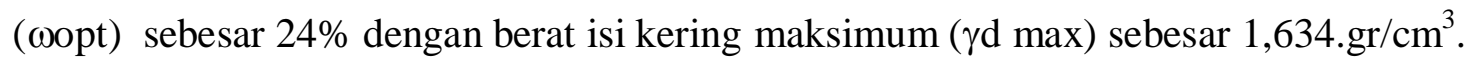

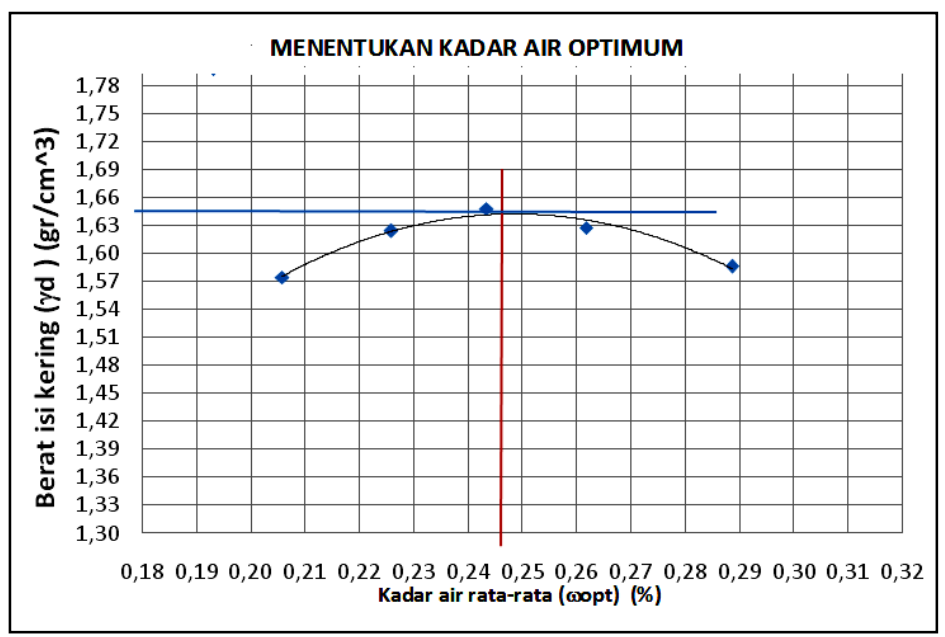

Gambar 4. Grafik Pemadatan Tanah Standar.

\section{Hasil Pengujian Kuat Geser Langsung (Direct Shear)}

Pengujian Direct Shear bertujuan untuk mengetahui nilai kuat geser tanah seperti nilai c (kohesi), nilai $\phi$ (sudut geser dalam) dan nilai $\tau$ (kuat geser). Hasil pengujian Direct Shear untuk nilai c (kohesi) ditujukkan dalam tabel 2 dan gambar 5 berikut : 
Tabel 2. Nilai Kohesi (c)

\begin{tabular}{|c|c|c|c|c|}
\hline \multirow{2}{*}{ Kode } & \multicolumn{3}{|c|}{ Nilai Kohesi c $(\mathrm{kPa})$} & \multirow{2}{*}{ Rata-rata } \\
\cline { 2 - 4 } & 1 & 2 & 3 & \\
\hline Tanah Merah Asli & 28,92 & 27,36 & 29,90 & 28,73 \\
\hline SBK 5\% & 65,41 & 71,08 & 83,16 & 73,22 \\
\hline SBK 10\% & 52,43 & 39,59 & 46,92 & 46,31 \\
\hline SBK 15\% & 54,93 & 38,01 & 54,05 & 49,00 \\
\hline SBK 20\% & 24,22 & 44,23 & 32,00 & 33,48 \\
\hline SBK 25\% & 23,10 & 26,21 & 31,50 & 26,94 \\
\hline
\end{tabular}

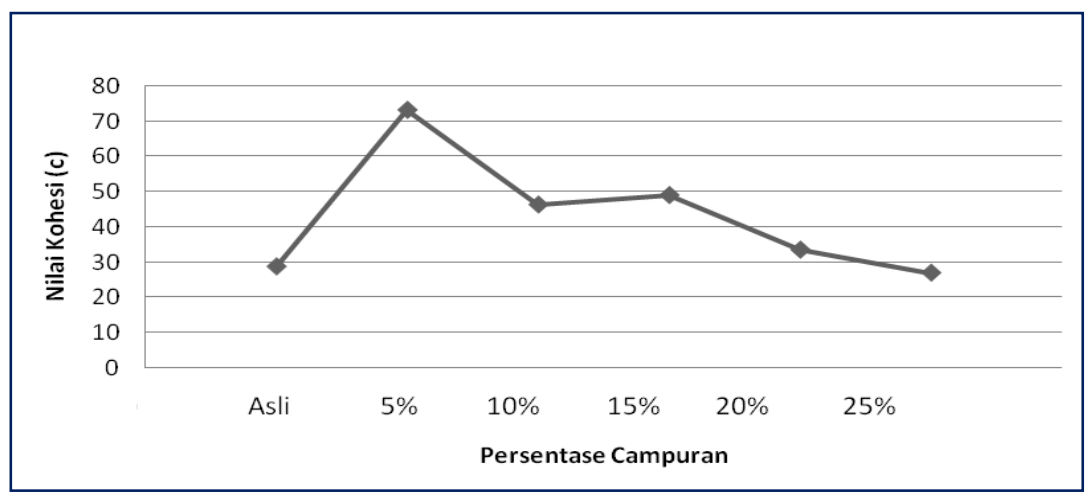

Gambar 5. Grafik Nilai Kohesi (c)

Dari grafik diatas nilai kohesi (c) tertinggi terlihat pada campuran serbuk biji karet sebanyak 5\% dengan nilai 73,22 $\mathrm{kPa}$

Hasil pengujian Direct Shear untuk nilai $\phi$ (sudut geser dalam) ditujukkan dalam tabel 3 dan gambar 6 berikut :

Tabel 3. Nilai Sudut Geser Dalam $(\phi)$

\begin{tabular}{|c|c|c|c|c|}
\hline \multirow{2}{*}{ Kode } & \multicolumn{3}{|c|}{ Nilai sudut geser dalam $\phi$} & \multirow{2}{*}{ Rata-rata } \\
\cline { 2 - 4 } & 1 & 2 & 3 & \\
\hline Tanah Merah Asli & 60,04 & 62,73 & 56,06 & 60,61 \\
\hline SBK 5\% & 41,25 & 31,08 & 7,23 & 34,11 \\
\hline SBK 10\% & 31,63 & 28,89 & 14,68 & 25,07 \\
\hline SBK 15\% & 29,20 & 47,85 & 36,97 & 38,01 \\
\hline SBK 20\% & 39,14 & 17,38 & 32,82 & 29,78 \\
\hline SBK 25\% & 54,18 & 34,64 & 27,56 & 38,79 \\
\hline
\end{tabular}

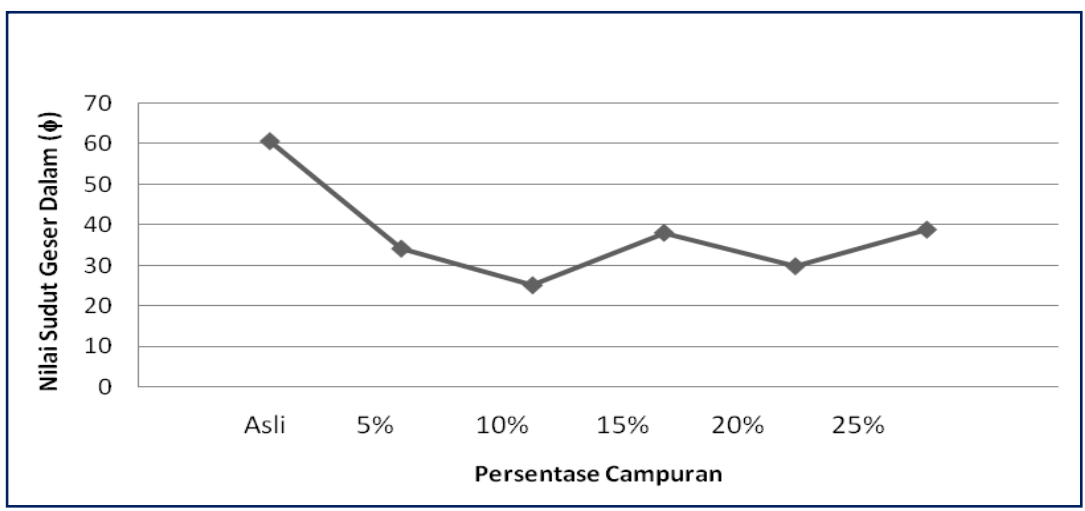

Gambar 6. Grafik Sudut Geser Dalam $(\phi)$ 
Dari grafik diatas nilai sudut geser dalam $(\phi)$ tertinggi terlihat pada campuran serbuk biji karet sebanyak $15 \%$ dengan nilai $38,01^{\circ}$

Hasil pengujian Direct Shear untuk nilai $\tau$ (nilai kuat geser) ditujukkan dalam tabel 4 dan gambar 7 berikut :

Tabel 4. Nilai Kuat Geser $(\tau)$

\begin{tabular}{|c|c|c|c|c|}
\hline \multirow{2}{*}{ Kode } & \multicolumn{3}{|c|}{ Nilai kuat geser dalam $\tau$} & \multirow{2}{*}{ Rata-rata } \\
\cline { 2 - 4 } & 1 & 2 & 3 & \\
\hline Tanah Merah Asli & 43,87 & 61,01 & 87,80 & 64,23 \\
\hline SBK 5\% & 72,96 & 10,46 & 87,57 & 57,00 \\
\hline SBK 10\% & 57,74 & 49,17 & 55,38 & 54,10 \\
\hline SBK 15\% & 59,75 & 57,18 & 80,18 & 65,70 \\
\hline SBK 20\% & 31,24 & 46,48 & 54,87 & 44,20 \\
\hline SBK 25\% & 35,04 & 38,20 & 49,62 & 40,95 \\
\hline
\end{tabular}

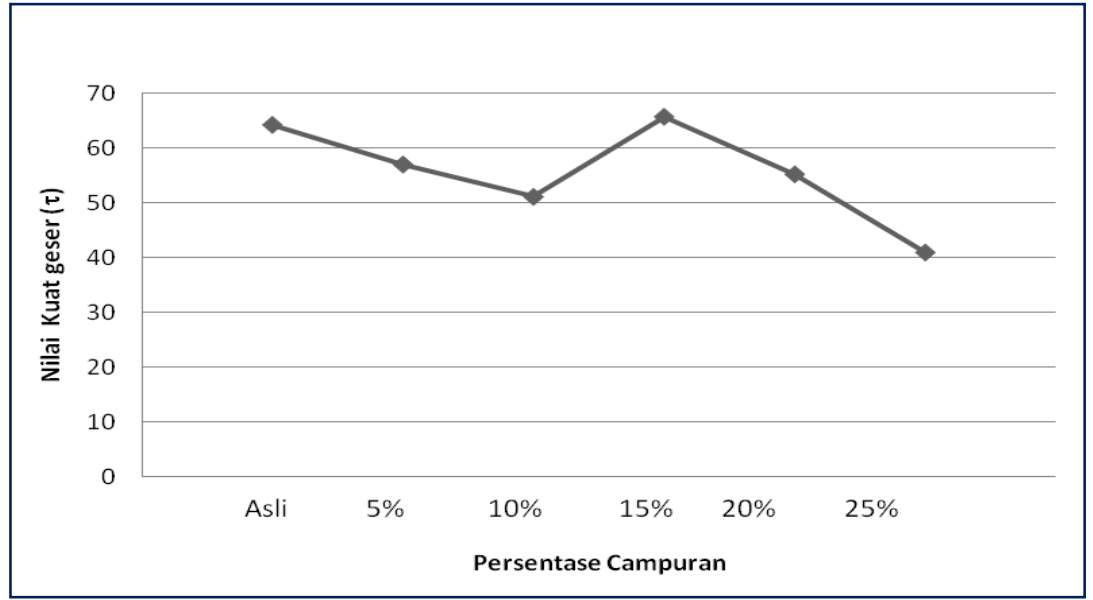

Gambar 7. Grafik Kuat Geser $(\tau)$

Dari grafik diatas nilai Kuat Geser $(\tau)$ tertinggi terlihat pada campuran serbuk biji karet sebanyak $15 \%$ dengan nilai $65,70 \mathrm{kPa}$.

\section{KESIMPULAN}

Dari penelitian ini, dapat ditarik kesimpulan :

1. Hasil pengujian indeks propertis menunjukkan bahwa tanah merah daerah Pakjo Palembang memiliki kadar air asli ( $\omega)$ sebesar 27,70 \%, berat jenis tanah (Gs) sebesar 2,67, batas cair (LL) 63,65\%, batas plastis (PL) 25,13\% dan indeks plastisitas (IP) sebesar 38,22 \%. Berdasarkan sistem klasifikasi USCS adalah tanah lempung atau $\mathrm{CH}$ dan berdasarkan sistem klasifikasi AASHTO adalah A-7-6 (clavey soils).

2. Hasil pengujian pemadatan tanah standar(PTS) didapatkan kadar air optimum sebesar $24 \%$ dengan berat isi kering optimum sebesar $1,634 \mathrm{gr} / \mathrm{cm}^{3}$

3. Hasil pengujian Direct Shear, tanah merah dicampur dengan serbuk biji karet (SBK) pada campuran SBK $15 \%$ kuat geser tanah merah meningkat $65,70 \mathrm{kPa}$ dengan nilai kohesi (c) 49,00 $\mathrm{kPa}$ dan nilai sudut geser dalam $(\phi) 38,01^{\circ}$ 


\section{DAFTAR PUSTAKA}

Bowles, Joseph E (1993). Sifat -sifat fisis tanah dan geoteknis tanah (mekanika tanah). Erlangga Jakarta.

Das, B., M., (2008). Mekanika Tanah 1. Erlangga, Jakarta.

Isa Darnawijaya, (1990). Buku Diktat Geografi Tanah, 2009: Universitas Negeri Yogyakarta.

Lindawati, M. Z. (2018). Analisis Pegaruh Penambahan Biji Karet Pada Campuran Beton Terhadap Kuat Tekan Beton K-175. Jurnal Deformasi, 3(1), 46-54.

Prasetyo, 2009. Tanah merah Dari Berbagai Bahan Induk Di Indonesia, Bogor.

Purwanto, H., Setiobudi, A., \& Rustam, R. K. (2020). Stabilization of soft clay soil using a gypsum plafond waste based on CBR testing. Int. J. Sci. Technol. Res, 9(2), 963968.

Rustam, R. K., \& Amiwarti, A. (2017). Karakteristik Kuat Geser Tanah Merah. Simposium II UNIID 2017, 2(1), 394-399.

Rustam, R. K., Purwanto, H., Adiguna, A., \& Putri, I. T. (2020). Pengaruh Penambahan Abu Arang Tempurung Kelapa Terhadap Kuat Geser Tanah Lempung di Daerah Makarti Jaya. Jurnal Deformasi, 4(2), 86-95.

Rustam, R. K., Resti, A., Purwanto, H., \& Muhammad, F. (2019, September). The effect of gypsum plafond waste on shear strength of soft clay soil. In IOP Conference Series: Materials Science and Engineering (Vol. 620, No. 1, p. 012039). IOP Publishing. 